\title{
Hope at last for foreign nurse recruitment?
}

An infuriating logjam in the enlistment of vitally needed foreign qualified nurses for South Africa stands to be broken with the hiring of the dynamic rural healthworker recruitment NGO, Africa Health Placements (AHP) - but bureaucrats will need to add their own muscle to clear two vital obstructions.

\section{At present all foreign nurses} fly here to write the exam and apply, fly back, wait ... it's time consuming and expensive, with no guaranteed outcome. Then there's all the back and forth of documents for verification, especially when one vital piece of information is missing. If the nursing council just automated their application into a computerised form.

The famously slow-moving SA Nursing Council (SANC) must streamline and simplify its cumbersome and outdated examination requirements (at least to bring them in line with those for foreign qualified doctors), and the government must urgently increase nursing accommodation in rural areas. With just these two key 'logs' moved, the hundreds of foreign qualified nurses who meet minimum local standards and annually knock on

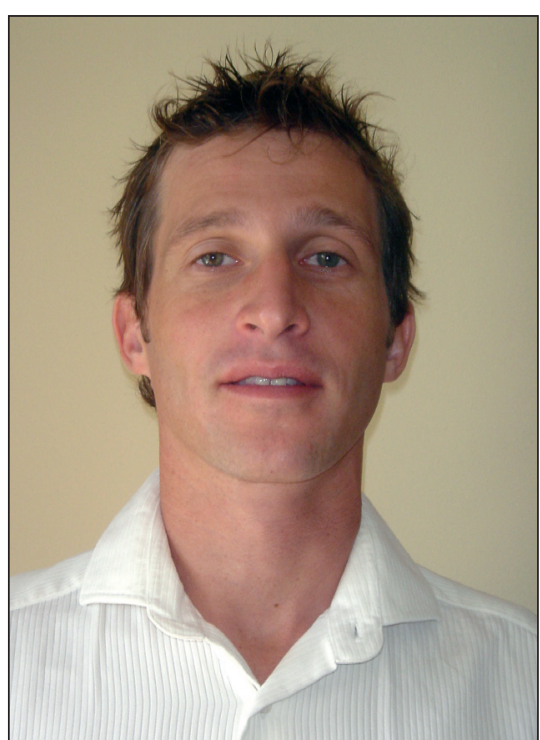

Saul Kornik, CEO of Africa Health Placements. official and NGO doors, could begin pouring in to help in the important revitalisation of primary health care and delivery of the all-embracing nurse-dependent National Health Insurance (NHI). This is according to the CEO of AHP, Saul Kornik, whose seven-year-old organisation has outstripped all government agencies and universities in identifying and placing healthcare workers in rural public sector posts. He doesn't expect it to be smooth sailing given the endorsement needed from the various health departments, SANC requirements, finding the appropriate rural vacancy and securing a provincial job offer. However, AHP staffers are veterans at negotiating most of this territory on behalf of applicants.

\section{Create a 'non-exam track' of properly qualified candidates}

Kornik says if the SANC just emulates the Health Professions Council (HPCSA) in identifying countries whose medical qualifications match local requirements to create a 'non-exam track' category of applicants, the waiting times would immediately drop by six months and his strike rate would soar. 'At present all foreign nurses fly here to write the exam and apply, fly back, wait ... it's time consuming and expensive, with no guaranteed outcome. Then there's all the back and forth of documents for verification, especially when one vital piece of information is missing. If the nursing council just automated their application into a computerised form that doesn't allow you to continue until all requirements are in, that would also speed up things dramatically. These bureaucratic and unnecessary 'hoops' were hugely off-putting for foreign qualified nurses, of whom there were many more than government departments and the nursing council seemed to realise. 'Thousands of nurses have approached us to work here over the years, but most just lose interest when they see all the hassle. So far our focus been mainly on placing doctors in rural public sector facilities, he said. With a nonexam category of applicants, nurses from countries like the United States, Western Europe, Canada, Australia and New Zealand would immediately be available while those from countries where qualifications were not always up to local standards would appropriately be required to write the local exam. The AHP, in spite of its historical focus, has recruited 60 foreign qualified nurses, but it's in the other healthcare fields that it has really shone. It has placed 2600 healthcare workers in the public sector since 2005, 1500 of them foreign qualified doctors. For doctors, this is more than the country's combined annual university medical school output (a miniscule percentage of whom choose to 'go rural' after serving their internship and discharging their community service obligations).

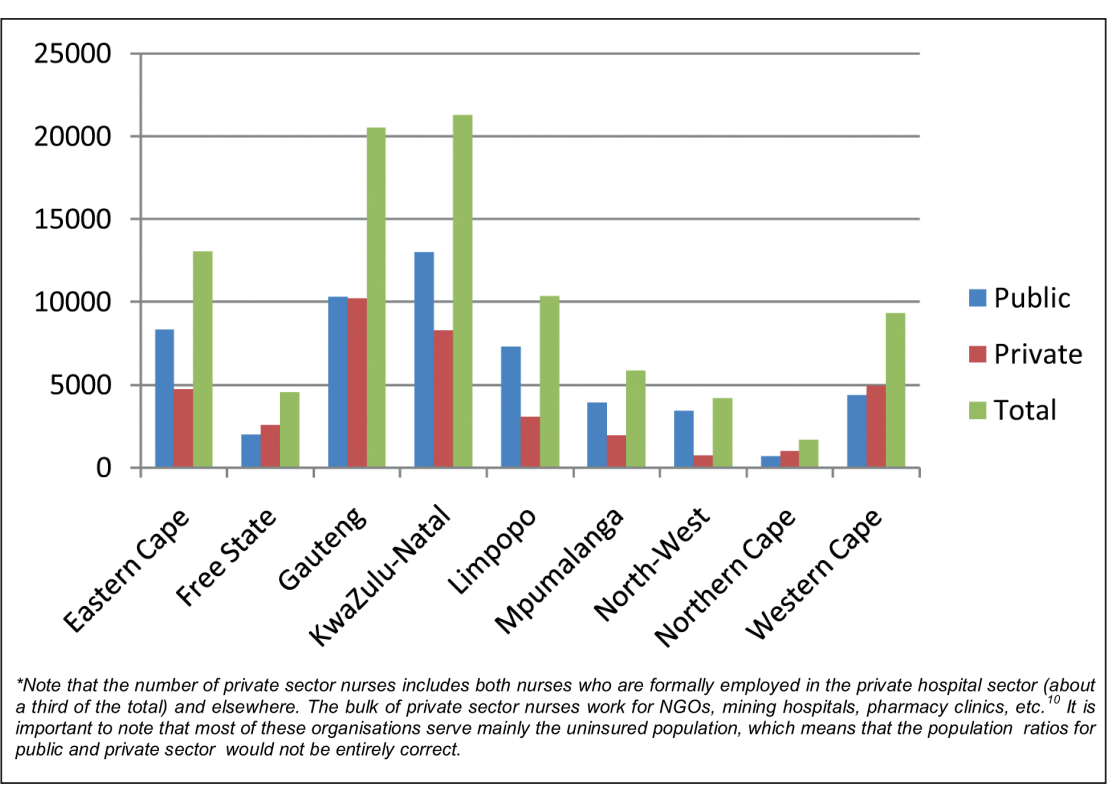

Number of professional nurses working in the private and public sector, by province: 2010. 
The desperate need is best illustrated by the following facts. Nearly half of South Africa's population lives in rural areas, where just $19 \%$ of the nation's nurses work. According to the government's White Paper on Human Resources for Health, nursing numbers dropped by 10000 between 1996 and 2008 (nursing colleges closed in 2007, after which specialist nurse numbers plummeted even faster, especially in intensive care, advanced midwifery and psychiatry). The white paper reveals the current nursing workforce to be ageing, with $46 \%$ of nurses over 50 years old and $16 \%$ already at retirement age (60). Most worryingly, it says that just to sustain the current ratio of nurses-to-population, 51200 nurses must qualify over the next decade, clearly an impossible task.

\section{Health minister eager to support acceleration}

Kornik said nurse accommodation was very thin on the rural ground while nurse salaries were much less competitive than those of doctors, two factors which if even partially addressed would make a rural nursing stint of one to three years for a foreigner far more attractive. He is optimistic that national health minister, $\mathrm{Dr}$ Aaron Motsoaledi, will move mountains to solve these two problems, given that doing so is vital to achieving his overall NHI goals. (The NHI plan requires 260 locally-hard-to-come-by specialist nurses to carry out three vital primary healthcare delivery objectives. These include, for each of the 52 health districts, the following: an advanced midwife, advanced paediatric nurse and an advanced primary health care nurse for the District Specialist Support Team, a professional nurse for the School Health Programme and a specialist primary health nurse for the municipal-ward-based Primary Health Care agency.)

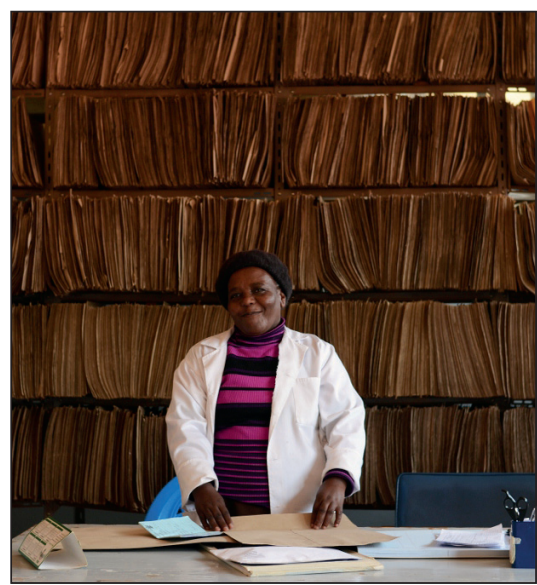

Undaunted. A nurse-clerk with patient files at St Lucy's Hospital, Tsolo in the Eastern Cape.

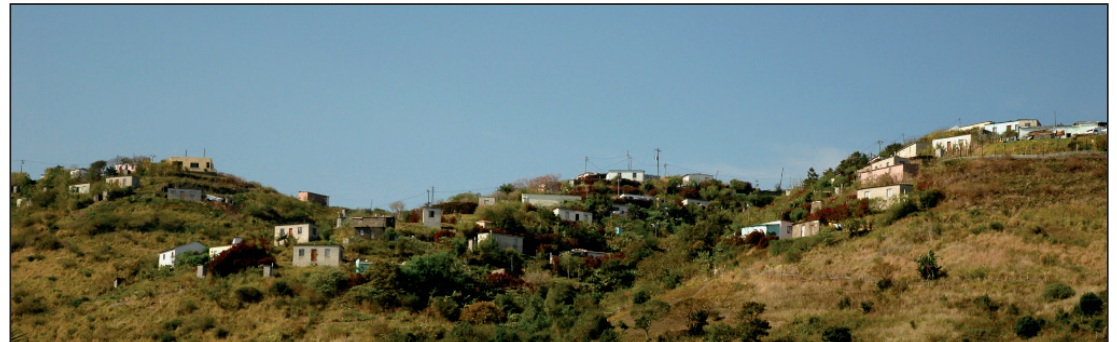

Patients drain from such terrain to far-off, poorly-staffed hospitals.

Table 1. The Health Department's 2008 Workforce Forecast Model

\begin{tabular}{llllll}
\hline & \multicolumn{5}{l}{ Gap in critical health professionals } \\
\hline Staff name & Base year & $\mathbf{2 0 1 1}$ & $\mathbf{2 0 1 5}$ & $\mathbf{2 0 2 0}$ & $\mathbf{2 0 1 5}$ \\
Enrolled nursing assistants & -8381 & -6434 & 1993 & 1304 & -723 \\
Enrolled nurses & 21010 & 22471 & 4470 & 4061 & 3046 \\
Staff nurse & -20138 & -19805 & -15380 & -8990 & -1357 \\
Professional nurses & -20736 & -22352 & -22121 & -11527 & -898 \\
Medical practitioners & -4145 & -4294 & -3930 & -2820 & -1213 \\
Medical specialists & -7590 & -7471 & -5677 & -3158 & -583 \\
Dental practitioners & 0 & 168 & 480 & 603 & 519 \\
Dental specialists & -22 & -24 & -21 & 2 & 13 \\
Community health worker & -11689 & -146651 & -14279 & -3006 & 152 \\
Home-based care worker & -7360 & -9655 & -9874 & -2079 & 197 \\
Other & -23911 & -20995 & -2096 & 8135 & 9414 \\
Total & -82962 & -83043 & -66435 & -17475 & 8568 \\
$\%$ of total & N/A & $100 \%$ & $100 \%$ & $100 \%$ & $100 \%$
\end{tabular}

The AHP collaboration with the Nursing Council comes in the form of a memorandum of understanding, signed in May this year. It will see a full-time AHP administrator seconded to the SANC'S foreign qualified nurse registration department. This person, with AHP staff backing, will screen applicants to ensure that only complete documentation is submitted to the SANC. Active recruitment starts within six months. Kornik is eagerly awaiting the new USAID/ PEPFAR funding cycle which begins on 1 October to see how his expanded funding application (to include foreign nurse recruitment) pans out. In the meantime he's slotting the nurse recruitment initiative into his overseas marketing and identifying the nursing needs of the worst-off rural hospitals so he can earmark and forewarn provinces willing and able to shell out the necessary salaries (not always a given). 'We'll be driven by the needs of the provincial departments of health and we'll certainly concentrate on getting more senior and more specialised nurses to help out with on-site training. We're most certainly not after economic migrants though we may help out some of the African nurses already here to secure permanent positions. We're after people willing to contribute to the developing world for one to three years,' Kornik said.

SA Nursing Council Registrar, $\mathrm{Mr}$ Tendani Mabuda, told journalists initially that the SANC and the AHP would form a management task team with two representatives from each party to 'co-manage' the implementation of the agreement. In spite of numerous attempts by Izindaba to contact Mabuda, he did not respond to the vexing question of streamlining foreign recruitment. The SANC's media relations department said such complex matters were best dealt with by Mabuda.

\section{Chris Bateman}

chrisb@hmpg.co.za

Figures from: Human Resources for Health for South Africa 2030. Draft HR Strategy for the Health Sector: 2012/13 - 2016/17. Consultation Document. August 2011. http://www.doh.gov.za/docs/ stratdocs/2011/draftHRstrategy_Consultation.pdf

S Afr Med J 2012;102(9):723-724 .

DOI:10.7196/SAMJ.6186 